\title{
Influence of amorphous silicon carbide intermediate layer in the back-contact structure of $\mathrm{Cu}_{2} \mathrm{ZnSnSe}_{4}$ solar cells
}

\author{
M. Colina, I. Martín, S. Giraldo, Y. Sánchez-González, R. Kondrotas, F. Oliva, V. Izquierdo-Roca, \\ A. Pérez-Rodríguez, A. Coll, R. Alcubilla, E. Saucedo
}

\begin{abstract}
CZTS thin film solar cells have been qualified as potential competitors of the more established CIGS ones. One of the more important handicaps of CZTS solar cells is the opencircuit voltage deficit. The rear-contact/absorber interface is known to be very sensitive to the formation of secondary phases, which are detrimental for the electrical behavior of the photovoltaic devices. The addition of intermediate layers to favor the formation of an adequate interface has been repeatedly tested. In this work, an amorphous silicon carbide (a-SiC) layer is added to explore its influence on the material properties and electrical performance of CZTSe solar cells. According to SEM analysis, when the a-SiC layer thickness is increased, bigger grains along the absorber are obtained. Additionally, a lower $\left[\mathrm{V}_{\mathrm{Cu}}+\mathrm{Zn}_{\mathrm{Cu}}\right]$ defect cluster density is also deduced from the analysis of Raman measurements. Both results indicate a favorable impact of a-SiC films on the material quality of the absorber. Fabricated solar cells show an enhancement of $0.9 \%$ abs. of efficiency compared to identical solar cells without a-SiC layers used as a reference. This increase is mainly related to an improvement of open-circuit voltage and fill factor when the proposed intermediate layer is included.
\end{abstract}

Index Terms - Silicon carbide, $\mathrm{Cu}_{2} \mathrm{ZnSn}\left(\mathrm{S}_{1-\mathrm{y}} \mathrm{Se}_{\mathrm{y}}\right)_{4}$, thin-film solar cells, surface passivation layer.

\section{INTRODUCTION}

$\mathrm{T}$ $\mathrm{HE} \mathrm{Cu}_{2} \mathrm{ZnSn}\left(\mathrm{S}_{1-\mathrm{y}} \mathrm{Se}_{\mathrm{y}}\right)_{4}(\mathrm{CZTS})$ solar cells are already a potential alternative to more mature $\mathrm{CuIn}_{\mathrm{x}} \mathrm{Ga}_{1-\mathrm{x}} \mathrm{Se}_{2}$ (CIGS) ones due to their reduced environmental impact and the relatively lower cost because of the abundance of their

Manuscript received March 4, 2016. This research was supported by MINECO (Ministerio de Economía y Competitividad de España) under the NOVACOST project (PCIN-2013-128-C02-01) and by EEEA-Grant program under the project FLEXART. Authors from IREC and the University of Barcelona belong to the M-2E (Electronic Materials for Energy) Consolidated Research Group and the XaRMAE Network of Excellence on Materials for Energy of the "Generalitat de Catalunya". Y.S. thanks the MINECO for the PTA fellowship (PTA2012-7852-A) and E.S. for the "Ramon y Cajal" fellowship (RYC-2011-09212).

M. Colina, S. Giraldo, Y Sánchez-González, R. Kondrotas, F. Oliva, V. Izquierdo-Roca, A. Pérez-Rodríguez, E. Saucedo are with Catalonia Institute for Energy Research (IREC), Jardins de les Dones de Negre 1, 08930 Sant Adrià del Besòs, Barcelona, Spain (e-mail: mcolina@irec.cat; sgiraldo@irec.cat; ysanchez@irec.cat; rkondrotas@irec.cat; foliva@irec.cat; vizquierdo@irec.cat; aperezr@irec.cat; esaucedo@irec.cat).

A. Pérez-Rodríguez is with $\mathrm{IN}^{2} \mathrm{UB}$, Departament d' Electrònica, Universitat de Barcelona, Martí i Franquès 1, 08028 Barcelona, Spain (e-mail: aperezr@irec.cat).

I. Martín, A. Coll, R. Alcubilla are with the Departament d'Enginyeria Electrònica, Universitat Politècnica de Catalunya, 08034 Barcelona, Spain (email: isidro.martin@upc.edu; arnau.coll@upc.edu; ramon.alcubilla@upc.edu). elements [1][2][3]. The record efficiency reported so far for a CZTS solar cell corresponds to $12.6 \%$ [4] whereas values around $22.0 \%$ have been already reached for CIGS solar cells [5]. The clear difference between the reported efficiencies of both technologies demonstrates that the CZTS is still a challenging technology with significant room for improvement. One of the main challenges of CZTS solar cells is the optimization of the back contact interface where decomposition reactions appear in both the molybdenum back contact and the absorber [6][7][8].

In order to overcome this decomposition reaction and to inhibit the formation of a thick $\mathrm{MoS}_{2}$ layer, multiple studies based on the addition of intermediate layers between the absorber and the molybdenum back contact have been proposed [10][11][12]. In this sense, different materials such as $\mathrm{Ag}$ [12][13], $\mathrm{ZnO}$ [10][11], $\mathrm{TiB}_{2}$ [14], TiN [9], Carbon [15] and $\mathrm{MoO}_{2}$ [16] were successfully tested leading to an enhancement of the solar cell electrical performance. The effects on the structural and electrical properties of the cells strongly depend on the nature of the material selected as intermediate layer. In the case of the Ag layers, not only the inhibition of $\mathrm{MoS}_{2}$ and others secondary phases is observed but also the doping with n-type atoms coming from the $\mathrm{Ag}$ layer is also reported [12]. Recently, the addition of an intermediate $25 \mathrm{~nm}$ carbon layer leading to an improvement of the short-circuit current density of CZTS solution-based solar cells was presented [15]. Therefore, it is quite accepted that investigations on different types of materials acting as sulfurization or selenization barrier of the Mo-contact and avoiding decomposition are more than valuable for the achievement of an improved absorber.

Amorphous silicon carbide (a-SiC) is a dielectric material commonly used for surface passivation and window layer in silicon solar cells [17][18][19][20] and insulator layer in film transistors [21][22]. Apart from its excellent electronic passivation properties for c-Si surfaces, a-SiC has shown a very good thermal stability [22]. Additionally, as an excellent dielectric material, it can be potentially applied as dielectric barrier for modularization in conductive substrates like steels. Given the electrical and structural features of silicon carbide, in this work we explore the influence of an a-SiC layer in the rear side structure of CZTS solar cells. The influence of this intermediate layer on the material quality of the absorber and electrical performance of solar cells is presented. 


\section{EXPERIMENTAL}

The rear contact of the pure selenide kesterite solar cells consists of a complex structure formed by different layers. Firstly, a stack of three layers of molybdenum with a total thickness of $750 \mathrm{~nm}$ was the first structure deposited onto the glass substrate. This stack exhibited a sheet resistance of $0.54 \Omega /$ sq. and is expected to be quite resistant to selenium incorporation due to its compactness. The methodology of preparation and a deeper explanation of the Mo structure can be found elsewhere[10][16][23]. Secondly, an intermediate layer of a-SiC was included on the top of the Mo tri-layer structure as shown in figure 1. Finally, due to the dielectric nature of the a-SiC, a single sacrificial molybdenum layer of about $30 \mathrm{~nm}$ thickness was arranged onto the intermediate a$\mathrm{SiC}$ layer to generate the required ohmic contact for hole extraction. This layer is more conductive $(0.25 \Omega / \mathrm{sq}$.) and is expected to be partially selenized after the absorber synthesis. The a-SiC layers were deposited by means of Plasma Enhanced Chemical Vapor Deposition (PECVD) using the experimental set-up and conditions described by Colina et al. [24]. Two different thicknesses of a-SiC were grown (5 and 10 $\mathrm{nm})$ according to the structure shown in figure 1 . A reference sample with no a-SiC layer was also prepared as control.

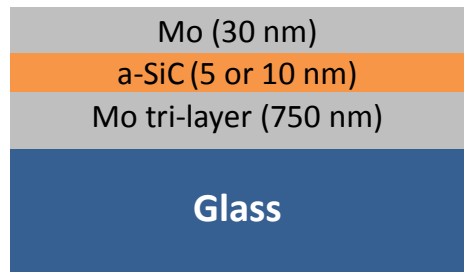

Fig. 1. Rear-contact structure used for the CZTSe solar cells

For the absorber preparation, three different metals $(\mathrm{Cu}, \mathrm{Zn}$ and $\mathrm{Sn}$ ) were sequentially sputtered onto the prepared back contacts. Subsequently, a 2-step reactive annealing process in a Se-Sn atmosphere was used for the synthesis of the absorbers according to the experimental sequence reported by Neuschitzer et al. [23]. In order to finish the solar cells, a $50 \mathrm{~nm} \mathrm{CdS}$ layer was deposited by means of Chemical Bath Deposition (CBD) following the procedure described elsewhere [25]. Afterwards, an intrinsic $\mathrm{ZnO}$ window layer and a transparent conductive oxide (ITO) were deposited by DC sputtering. Finally, individual cells of $3 \times 3 \mathrm{~mm}^{2}$ were mechanically scribed on each one of the fabricated samples.

Regarding morphological characterization, absorber layers with the different back-contact structures were evaluated by field emission scanning electron microscopy (FESEM) through a Zeiss series Auriga microscope using an accelerating voltage of $5 \mathrm{kV}$. Furthermore, an X-ray florescence spectrometer (Fisherscope XVD) was used to evaluate the relative concentration of elements in the precursors and absorbers. In order to further evaluate the impact of a-SiC layer on the absorber properties, Raman measurements on the CZTSe surface and CZTSe/Mo interface were performed. For that purpose, an iHR320 Horiba Jovin Yvon spectrometer coupled to a Raman probe (developed at
IREC) by an optical fiber was employed. The spectra acquisition was performed using the backscattering configuration with an excitation wavelength of $532 \mathrm{~nm}, 70 \mu \mathrm{m}$ spot size and a power density lower than $1 \mathrm{~kW} / \mathrm{cm}^{2}$. All Raman spectra have been calibrated by using monocrystalline silicon as reference and by imposing its main Raman mode at $520 \mathrm{~cm}^{-1}$. Raman measurements from back-CZTSe side and $\mathrm{MoSe}_{2}$ side were performed on the layers after the mechanical removal (lift off) using a methodology similar to that reported in reference [26].

Regarding electrical characterization, an ABET Technologies Sun 3000 Class AAA solar simulator was employed for the solar cell J-V curve measurements. The spectral response was measured in a pre-calibrated Bentham PVE300 system, allowing the calculation of external quantum efficiency (EQE) values. Finally, a commercially available flash lamp coupled to a J-V acquisition system with a temperature controlled chuck was employed to obtain suns $-\mathrm{V}_{\mathrm{oc}}$ measurements of the cells. In this technique, the light intensity and open-circuit voltage $\left(\mathrm{V}_{\mathrm{oc}}\right)$ of the cell are simultaneously recorded. Since the device is under open-circuit conditions, no electrical current flows through it and the obtained data can be used to calculate a pseudo-J-V curve without ohmic losses. A detailed description of this technique can be found in Ref. [27].

\section{RESULTS AND DISCUSSION}

\section{A. Absorber material characterization}

As a first approach, we made Scanning Electron Microscopy (SEM) characterization of the absorbers after the recrystallization step. In figure 2 , we show a top-view and a cross-section SEM images for the three types of samples under study. As it can be seen, significantly bigger grain sizes are obtained when the a-SiC thickness increases. Interestingly, an $\mathrm{x}$-ray fluorescence analysis of the absorbers reveals no significant differences in the composition of different samples. All the prepared absorbers exhibit a ratio of about 0.79 for $\mathrm{Cu} / \mathrm{Zn}+\mathrm{Sn}, 1.17$ for $\mathrm{Zn} / \mathrm{Sn}$ and a $51 \%$ selenium concentration.

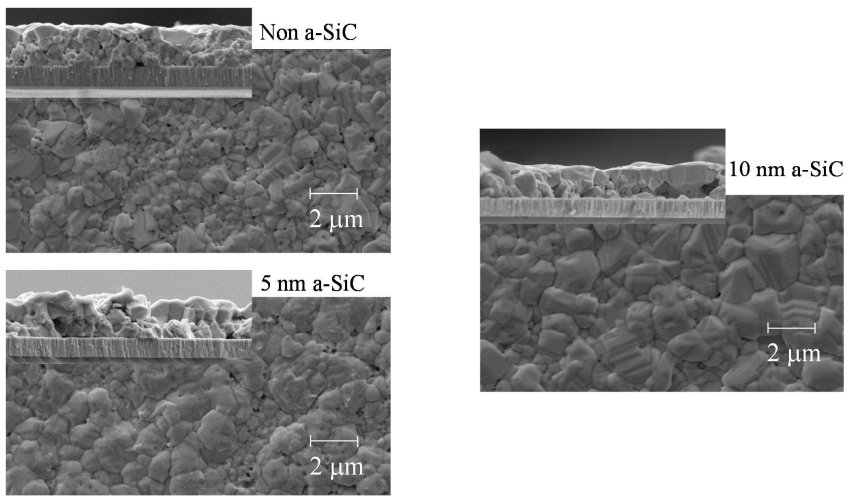

Fig. 2. SEM images of superficial and cross-section of the absorbers with and without the intermediate a SiC added in the back contact.

Regarding the Mo rear contact, we did not find significant differences in its morphology between the three samples (not shown in figure 2) suggesting that the introduction of a-SiC 
films do not impact on the molybdenum over-selenization. In our case, this detrimental effect is already minimized due to the combination of three molybdenum layers with different porosity at the rear contact. This characteristic could explain the similar results for all three samples. In addition, no evidence of continuous a-SiC layers is found after the reactive annealing process. This result indicates that the molybdenum layers on top and under the a-SiC films could be into contact after the high temperature step. As a consequence, it could be considered that the main impact of the introduction of such thin a-SiC films consists of an improvement in the absorber nucleation.

In order to get a deeper insight into the impact of a-SiC barrier layers on the absorber, a structural analysis based on Raman measurements was performed. Raman analysis for the front surface of the samples (figure 3a) shows the typical peaks of CZTSe phase with good crystal quality and $\mathrm{Cu}$ poor content [28][29]. These spectra are dominated by the contributions at $197 \mathrm{~cm}^{-1}$ and $170 \mathrm{~cm}^{-1}$ assigned respectively to $\mathrm{A}^{1}$ and $\mathrm{A}^{2}$ Raman modes [30]. No peaks attributed to secondary phases are observed. The analysis of the peaks' intensities based on M. Dimitrievska et al. work [28] was used. The areas of the $197 \mathrm{~cm}^{-1}$ and $170 \mathrm{~cm}^{-1}$ peaks were considered as $I_{1}$ and $I_{2}$ intensities, respectively. Finally, the ratio $\mathrm{I}_{2} /\left(\mathrm{I}_{2}+\mathrm{I}_{1}\right)$ is calculated leading to the results (black squares) shown in figure $3 \mathrm{~d}$. According to M. Dimitrievska et al., the ratio $\mathrm{I}_{2} /\left(\mathrm{I}_{2}+\mathrm{I}_{1}\right)$ is directly related to not only the $\left[\mathrm{V}_{\mathrm{Cu}}+\mathrm{Zn}_{\mathrm{Cu}}\right]$ defect cluster density [28] but also to the opencircuit voltage of the finished solar cell[31]. For the samples under study, this ratio depicts lower values (decrease of the $\left[\mathrm{V}_{\mathrm{Cu}}+\mathrm{Zn}_{\mathrm{Cu}}\right]$ defect clusters) when a thicker a-SiC barrier is employed (Figure 3(d)), which is correlated to a clear increase of $\mathrm{V}_{\mathrm{oc}}$ as it will be shown below.

After lift-off of the absorber from the glass/Mo substrates, further Raman analyses were carried out. The back side region of the absorber (figure $3 \mathrm{~b}$ ) presents the same Raman spectra features (a weak contribution at $240 \mathrm{~cm}^{-1}$ related to some residues of $\mathrm{MoSe}_{2}$ phase is observed) and the same trend for the $\mathrm{I}_{2} /\left(\mathrm{I}_{2}+\mathrm{I}_{1}\right)$ ratio with the a-SiC thickness (red circles in figure $3 d)$. In this case, a small difference of its $I_{2} /\left(I_{2}+I_{1}\right)$ ratio indicates that the absorber back surface contains a lower concentration of $\left[\mathrm{V}_{\mathrm{Cu}}+\mathrm{Zn}_{\mathrm{Cu}}\right]$ defect clusters. The comparison of the Raman features from the front and back region suggests a homogeneous material throughout the complete CZTSe volume. Finally, the substrate side assessment by Raman spectroscopy (figure 3c) confirms the formation of $\mathrm{MoSe}_{2}$ phase (peak at $240 \mathrm{~cm}^{-1}$ ) at the Mo/CZTSe interface with no significant difference between samples. This result indicates that contact selenization is related to the molybdenum structure more than on the presence of a-SiC films. On the other hand, the a-SiC free sample shows a clear evidence of CZTSe contribution, while it is not observed for the a-SiC containing samples. This result could be related to either a stronger adherence between the absorber and Mo layers without a-SiC layers that left some absorber material after substrate lift-off, or the presence of smaller CZTSe crystals at the interface region, already seen by SEM images.

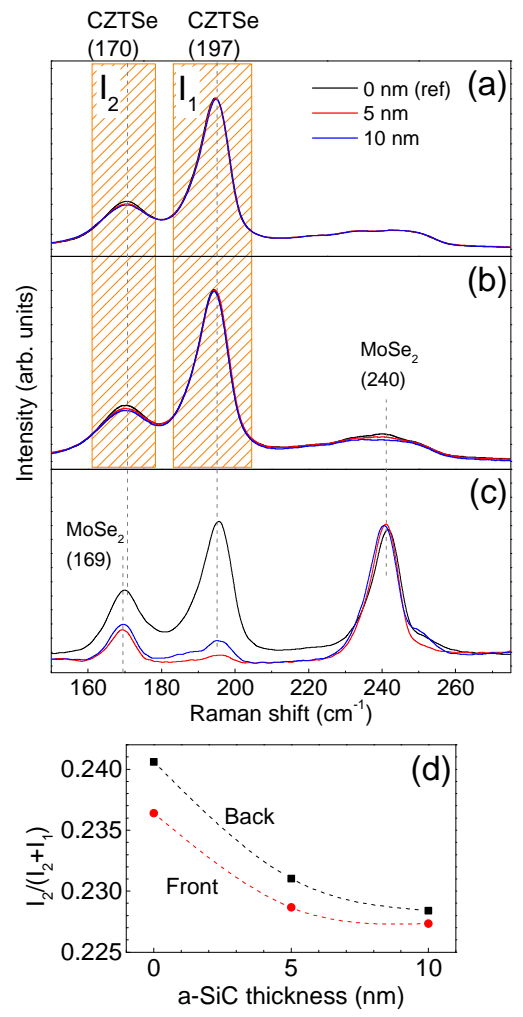

Fig. 3. (a), (b), (c) Raman spectra of the CZTSe absorbers synthesized onto absorber surface, absorber back surface, and back contact surface respectively. (d) $I_{1}$ and $I_{2}$ areas ratio of the front (red dots) and back (black squares) spectra for different a-SiC samples.

\section{B. Solar cell performance}

All the previous absorbers with different thicknesses of a-SiC were used to fabricate $3 \times 3 \mathrm{~mm}^{2}$ CZTSe solar cells. The statistical distribution of the photovoltaic figures for all the fabricated solar cells is presented in Figure 4. Additionally, Table 1 summarized the average values and the champion cell electrical performance for every a-SiC thickness under study. As it can be observed, an average improvement of $0.9 \%$ abs. in efficiency is obtained when adding $10 \mathrm{~nm}$ of a-SiC to the back-contact structure demonstrating the benefits of this layer in the rear contact of CZTSe solar cells.

TABLE I

AVERAGE AND BEST PHOTOVOLTAIC PARAMETERS OF THE FABRICATED SOLAR CELLS.

\begin{tabular}{cccccc}
\hline \hline $\begin{array}{c}\mathrm{a}-\mathrm{SiC} \\
(\mathrm{nm})\end{array}$ & $\begin{array}{c}\eta \\
(\%)\end{array}$ & $\begin{array}{c}\mathrm{V}_{\mathrm{oc}} \\
(\mathrm{mV})\end{array}$ & $\begin{array}{c}\mathrm{J}_{\mathrm{sc}} \\
\left(\mathrm{mA} / \mathrm{cm}^{2}\right)\end{array}$ & $\begin{array}{c}\mathrm{FF} \\
(\%)\end{array}$ & $\begin{array}{c}\mathrm{pFF} \\
(\%)\end{array}$ \\
\hline \multirow{2}{*}{0} & 5.6 & 360 & 27.9 & 54.5 & 66.2 \\
& $(6.6)$ & $(374)$ & $(29.6)$ & $(59.6)$ & \\
5 & 6.0 & 370 & 27.2 & 60.0 & 65.3 \\
& $(6.9)$ & $(381)$ & $(28.7)$ & $(63.5)$ & \\
& 6.5 & 381 & 28.8 & 59.0 & 65.5 \\
\hline \hline
\end{tabular}

Based on these data, we can see that open-circuit voltage $\left(\mathrm{V}_{\mathrm{oc}}\right)$ and fill factor (FF) improve with a-SiC directly impacting on the power conversion efficiency $(\eta)$. On the other hand, the short circuit current density $\left(\mathrm{J}_{\mathrm{sc}}\right)$ slightly 
decreases for $5 \mathrm{~nm}$ a-SiC compared to the reference sample and it improves for $10 \mathrm{~nm}$ a-SiC layers.

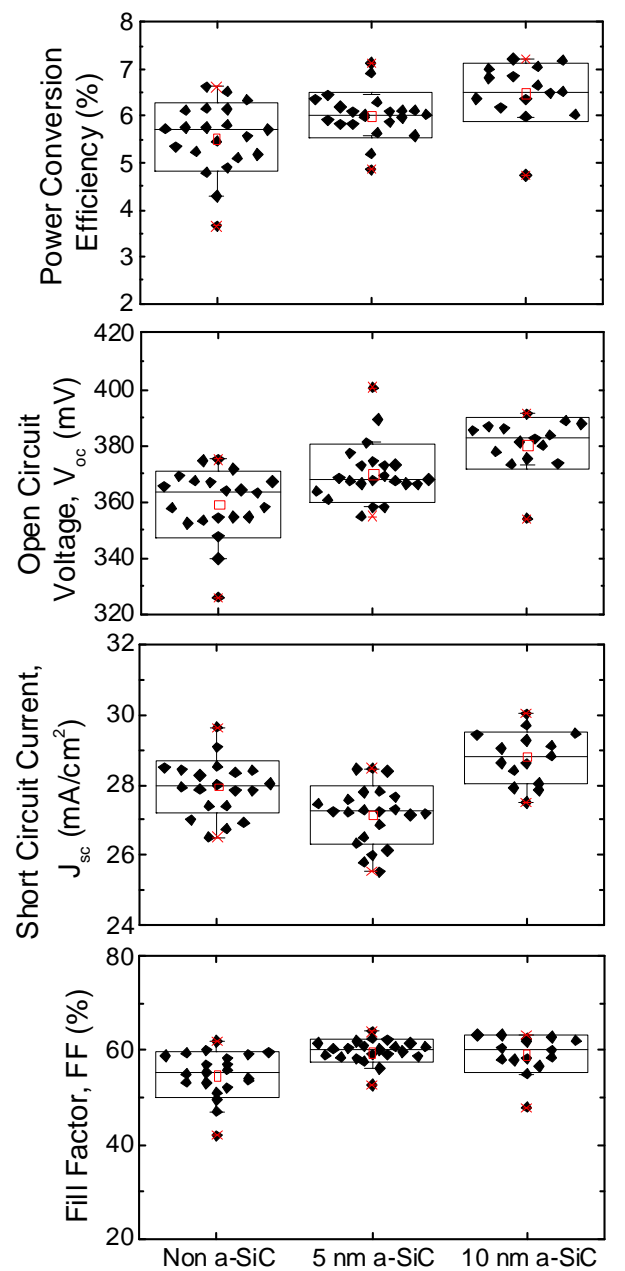

Fig. 4. Electrical performance of the CZTSe solar cells with three different thicknesses of a-SiC back-surface intermediate layer $(0,5$ and $10 \mathrm{~nm})$.

In order to get more information about this particular $\mathrm{J}_{\mathrm{sc}}$ behavior, the external quantum efficiency (EQE) of the solar cells with the highest $\mathrm{J}_{\mathrm{sc}}$ values for every a-SiC thickness was measured and the obtained data are presented in figure 5. Notice that $\mathrm{J}_{\mathrm{sc}}$ values for these cells follow the same trend than the averaged $\mathrm{J}_{\mathrm{sc}}$ values. As it can be observed in that figure, the samples with a-SiC layers show a steeper EQE dependence for photons with wavelengths beyond $1000 \mathrm{~nm}$. The absorption edge in CZTSe material is dominated by tail states [32]; thus, the steeper EQE dependence is related to a lower tail state density, i.e. a higher quality absorber. Furthermore, the spectral response in the range of 570 to $1000 \mathrm{~nm}$ is clearly improved with the $10 \mathrm{~nm}$ a-SiC layer indicating a better electrical response of the absorber, i.e. a reduction in carrier recombination. Both results agree with the previous material characterization where material quality is improved under the presence of a-SiC films: enlarged grain size (SEM results) and reduction of $\left[\mathrm{V}_{\mathrm{Cu}}+\mathrm{Zn}_{\mathrm{Cu}}\right]$ defect clusters (Raman results). As a consequence of these effects, the addition of a $5 \mathrm{~nm}$ a-SiC film results in a lower $\mathbf{J}_{\mathrm{sc}}$ mainly due to the lower absorption beyond $1000 \mathrm{~nm}$, which is responsible of a $0.62 \mathrm{~mA} / \mathrm{cm}^{2}$ loss compared to the reference sample. However, a thicker a-SiC film leads to a much better response resulting in a higher $\mathbf{J}_{\mathrm{sc}}$ value than the reference. Notice that in this case we are comparing solar cells with the highest $\mathrm{J}_{\mathrm{sc}}$ values, but the higher quality of the absorber is most likely behind the increase in the average value of $\mathrm{J}_{\mathrm{sc}}$ of $0.9 \mathrm{~mA} / \mathrm{cm}^{2}$ for $10 \mathrm{~nm}$ a$\mathrm{SiC}$ samples compared to the reference, as shown in Table 1 and Figure 4.

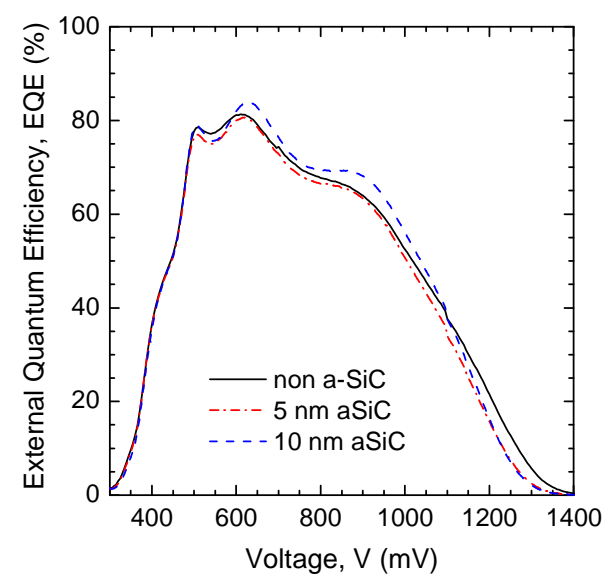

Fig. 5. External quantum efficiency of the best devices fabricated with the different thicknesses of a-SiC added in the back-contact of the cells.

Focusing on $\mathrm{V}_{\mathrm{oc}}$, a higher value of this parameter is always related to a lower carrier recombination within the device. As discussed above, the conclusions deduced from EQE data and material characterization point out to an absorber with better properties when a-SiC is included. Then, the improvement in the average $\mathrm{V}_{\mathrm{oc}}$ of about $20 \mathrm{mV}$ with $10 \mathrm{~nm}$ a-SiC layer could be attributed to longer carrier lifetimes, probably related to less grain boundaries as demonstrated by the SEM images (see figure 3).

Finally, the averaged FF values show a boost from $54.5 \%$ to $59.0-60.0 \%$ when the a-SiC is included. In order to determine the origin of this improvement, we performed suns$\mathrm{V}_{\text {oc }}$ measurements of the best cells. In this technique, a flash lamp is used and the light intensity and $\mathrm{V}_{\mathrm{oc}}$ of the cell are simultaneously measured [27]. Assuming a linear relationship between light intensity and $\mathrm{J}_{\mathrm{sc}}$, we can translate light intensity to current density and calculate an illuminated J-V characteristic. Notice that in such a curve, ohmic losses are not included since the device is kept under open-circuit conditions. The obtained curves are plotted in figure 6 together with the usual illuminated $\mathrm{J}-\mathrm{V}$ characteristics for a direct comparison. As expected, these curves have identical $\mathbf{J}_{\mathrm{sc}}$ and $\mathrm{V}_{\mathrm{oc}}$ than the usual ones but they are characterized by a pseudo-fill factor ( $\mathrm{pFF}$ ) where only the carrier transport mechanisms through the junction are considered. The calculated $\mathrm{pFF}$ values are shown in Table I with values in the $65-66 \%$ range for the three curves. This result indicates similar junction characteristics for all the samples under study and, thus, the difference in FF must be attributed to an improvement in ohmic losses. Given the material characterization results, a possible explanation to the significant FF improvement could be related to a bulk 
conductivity increase due to the presence of less grain boundaries along the vertical carrier flow throughout the sample.
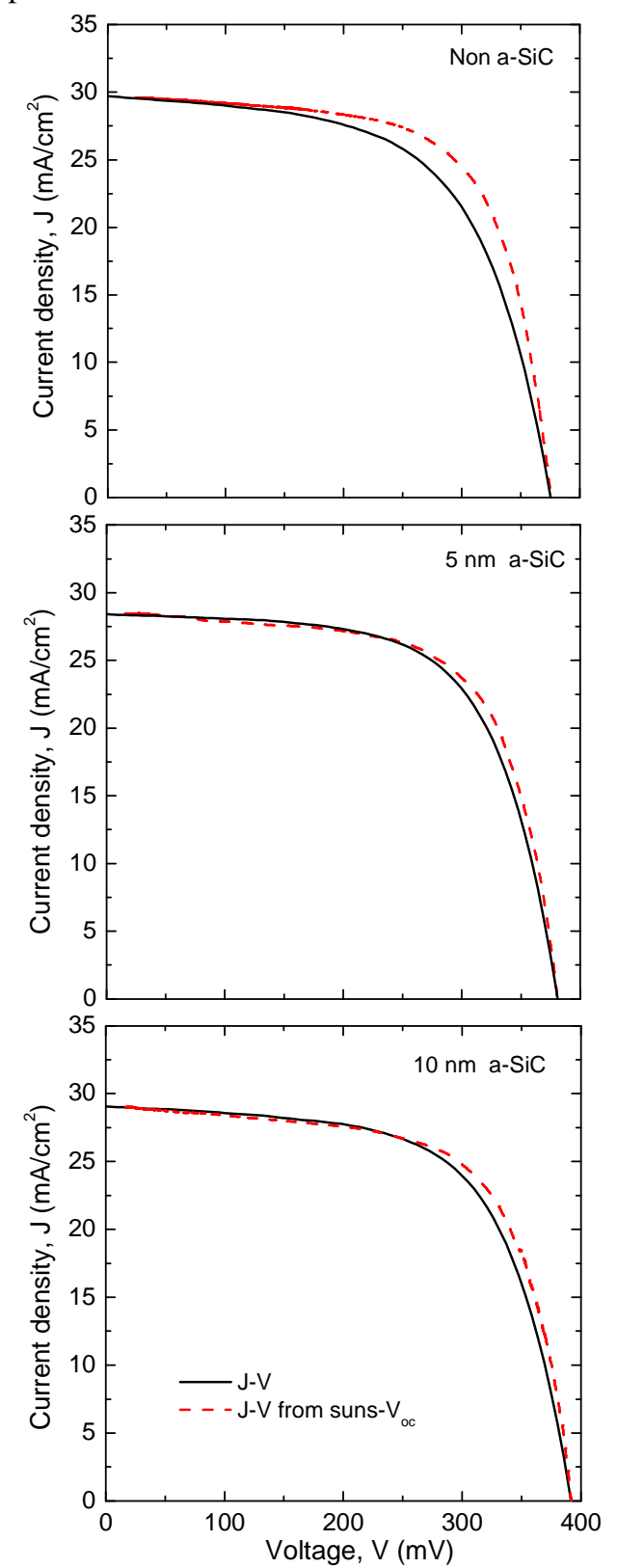

Fig. 6. J-V and J-V calculated from suns- $\mathrm{V}_{\mathrm{oc}}$ measurements characteristics for the best fabricated solar cells.

\section{CONCLUSIONS}

Amorphous silicon carbide has been used as intermediate layer in the back-contact structure of $\mathrm{Cu}_{2} \mathrm{ZnSnSe}_{4}$ solar cells. From SEM images, we conclude that the grain size of the CZTSe absorbers increases with the addition of the a-SiC layer. In addition, the Raman analysis indicates that there is a $\left[\mathrm{V}_{\mathrm{Cu}}+\mathrm{Zn}_{\mathrm{Cu}}\right]$ defect clusters decrease as the thickness of the a$\mathrm{SiC}$ increases which is correlated to a clear increase of $\mathrm{V}_{\mathrm{oc}}$ in the finished cells. The analysis of the averaged photovoltaic parameters of the fabricated solar cells demonstrates that efficiency improves with the addition of the a-SiC layer resulting in a efficiency increase of $0.9 \%$ abs for $10 \mathrm{~nm}$ thick a-SiC layers. In particular, the increase in $\mathrm{V}_{\text {oc }}$ and $\mathrm{J}_{\mathrm{sc}}$ could be attributed to lower carrier recombination suggested by the better absorber properties. Finally, FF improvement is associated to a reduction of ohmic losses, probably related to a higher bulk conductivity. As the main result of this work, we can conclude that the presence of a-SiC layers at the rear contact leads to a better quality of the absorber that positively impacts on device performance.

\section{REFERENCES}

[1] I. L. Repins, M. J. Romero, J. V. Li, S.-H. Wei, D. Kuciauskas, C.-S. Jiang, C. Beall, C. DeHart, J. Mann, W.-C. Hsu, G. Teeter, A. Goodrich, and R. Noufi, "Kesterite Successes, Ongoing Work, and Challenges: A Perspective From Vacuum Deposition,' IEEE J. Photovoltaics, vol. 3, no. 1, pp. 439-445, Jan. 2013.

[2] D. B. Mitzi, O. Gunawan, T. K. Todorov, and D. A. R. Barkhouse, "Prospects and performance limitations for $\mathrm{Cu}-\mathrm{Zn}-\mathrm{Sn}-\mathrm{S}-\mathrm{Se}$ photovoltaic technology Prospects and performance limitations for $\mathrm{Cu}-$ $\mathrm{Zn}-\mathrm{Sn}-\mathrm{S}$ - Se photovoltaic technology," Philos. transactions R. Soc. A, vol. 371, p. 20110432, July 2013.

[3] S. Siebentritt and S. Schorr, "Kesterites-a challenging material for solar cells," Prog. Photovoltaics Res. Appl., vol. 20, no. 5, pp. 512-519, Aug. 2012.

[4] W. Wang, M. T. Winkler, O. Gunawan, T. Gokmen, T. K. Todorov, Y. Zhu, and D. B. Mitzi, "Device Characteristics of CZTSSe Thin-Film Solar Cells with 12.6\% Efficiency," Adv. Energy Mater., vol. 4, no. 7, 1301465, May 2014.

[5] M. A. Green, K. Emery, Y. Hishikawa, W. Warta, and E. D. Dunlop, "Solar cell efficiency tables ( Version 45 )," Prog. Photovoltaics Res. Appl., vol. 23, pp. 1-9, 2015.

[6] J. T. Wätjen, J. J. Scragg, T. Ericson, M. Edoff, and C. PlatzerBjörkman, "Secondary compound formation revealed by transmission electron microscopy at the $\mathrm{Cu}_{2} \mathrm{ZnSnS}_{4} / \mathrm{Mo}$ interface," Thin Solid Films, vol. 535, pp. 31-34, May 2013.

[7] J. J. Scragg, J. T. Wätjen, M. Edoff, T. Ericson, T. Kubart and C. Platzer-Björkman, "A Detrimental Reaction at the Molybdenum Back Contact in,” J. Am. Chem. Soc., vol. 134, pp. 19330-19333, 2012.

[8] J. J. Scragg, T. Ericson, T. Kubart, M. Edoff, and C. Platzer-Björkman, "Chemical Insights into the Instability of $\mathrm{Cu}_{2} \mathrm{ZnSnS}_{4}$ Films during Annealing," Chem. Mater., vol. 23, no. 20, pp. 4625-4633, Oct. 2011.

[9] J. J. Scragg, T. Kubart, J. T. Wätjen, T. Ericson, M. K. Linnarsson, and C. Platzer-Björkman, "Effects of Back Contact Instability on $\mathrm{Cu}_{2} \mathrm{ZnSnS}_{4}$ Devices and Processes," Chem. Mater., vol. 25, no. 15, pp. 3162-3171, Aug. 2013.

[10] S. López-Marino, M. Placidi, A. Pérez-Tomás, J. Llobet, V. IzquierdoRoca, X. Fontané, A. Fairbrother, M. Espíndola-Rodríguez, D. Sylla, A. Pérez-Rodríguez, and E. Saucedo, "Inhibiting the absorber/Mo-back contact decomposition reaction in $\mathrm{Cu}_{2} \mathrm{ZnSnSe}_{4}$ solar cells: the role of a $\mathrm{ZnO}$ intermediate nanolayer," J. Mater. Chem. A, vol. 1, no. 29, p. 8338, 2013.

[11] W. Li, J. Chen, H. Cui, F. Liu, and X. Hao, "Inhibiting $\mathrm{MoS}_{2}$ formation by introducing a $\mathrm{ZnO}$ intermediate layer for $\mathrm{Cu}_{2} \mathrm{ZnSnS}_{4}$ solar cells," Mater. Lett., vol. 130, pp. 87-90, Sep. 2014.

[12] H. Cui, C. Lee, W. Li, X. Liu, X. Wen, and X. Hao, "Improving Efficiency of Evaporated $\mathrm{Cu}_{2} \mathrm{ZnSnS}_{4}$ Thin Film Solar Cells by a Thin $\mathrm{Ag}$ Intermediate Layer between Absorber and Back Contact,' Int. J. photoenergy, vol. 2015, 2015.

[13] H. Cui, X. Liu, F. Liu, X. Hao, N. Song, and C. Yan, "Boosting $\mathrm{Cu}_{2} \mathrm{ZnSnS}_{4}$ solar cells efficiency by a thin $\mathrm{Ag}$ intermediate layer between absorber and back contact," Appl. Phys. Lett., vol. 104, no. 4, p. 041115, Jan. 2014.

[14] F. Liu, K. Sun, W. Li, C. Yan, H. Cui, L. Jiang, X. Hao, and M. a. Green, "Enhancing the $\mathrm{Cu}_{2} \mathrm{ZnSnS}_{4}$ solar cell efficiency by back contact modification: Inserting a thin $\mathrm{TiB}_{2}$ intermediate layer at $\mathrm{Cu}_{2} \mathrm{ZnSnS}_{4} / \mathrm{Mo}$ interface," Appl. Phys. Lett., vol. 104, no. 5, p. 051105, Feb. 2014.

[15] F. Zhou, F. Zeng, X. Liu, F. Liu, N. Song, C. Yan, A. Pu, J. Park, K. Sun, and $\mathrm{X}$. Hao, "Improvement of Jsc in $\mathrm{Cu}_{2} \mathrm{ZnSnS}_{4}$ solar cell by using a thin carbon intermediate layer at $\mathrm{Cu}_{2} \mathrm{ZnSnS}_{4}$ /Mo interface.," ACS Appl. Mater. Interfaces, Sep. 2015. 
[16] S. Lopez-Marino, M. Espíndola-Rodríguez, Y. Sánchez, X. Alcobé, X. Fontané, H. Xie, M. Neuschitzer, S. Giraldo, M. Placidi, V. IzquierdoRoca, A. Pérez-Rodríguez, and E. Saucedo, "The importance of back contact modification in high efficiency $\mathrm{Cu}_{2} \mathrm{ZnSnSe}_{4}$ solar cells: the role of a thin $\mathrm{MoO}_{2}$ layer," Nano Energy, 2015.

[17] Y. Tawada, M. Kondo, H. Okamoto, and Y. Hamakawa, "Hydrogenated amorphous silicon carbide as a window material for high efficiency a-Si solar cells," Sol. Energy Mater., vol. 6, no. 3, pp. 299-315, Mar. 1982.

[18] S. Glunz, S. Janz, M. Hofmann, T. Roth, and G. Willeke, "Surface Passivation of Silicon Solar Cells using Amorphous Silicon Carbide Layers," in 2006 IEEE 4th World Conference on Photovoltaic Energy Conference, 2006, vol. 1, pp. 1016-1019.

[19] I. Martín, M. Vetter, a. Orpella, J. Puigdollers, A. Cuevas, and R. Alcubilla, "Surface passivation of p-type crystalline Si by plasma enhanced chemical vapor deposited amorphous $\mathrm{SiC}_{\mathrm{x}}: \mathrm{H}$ films," Appl. Phys. Lett., vol. 79, no. 14, p. 2199, 2001.

[20] M. Vetter, C. Voz, R. Ferre, I. Martín, a. Orpella, J. Puigdollers, J. Andreu, and R. Alcubilla, "Electronic properties of intrinsic and doped amorphous silicon carbide films," Thin Solid Films, vol. 511-512, pp. 290-294, Jul. 2006.

[21] K. J. Roe, G. Katulka, J. Kolodzey, S. E. Saddow, and D. Jacobson, "Silicon carbide and silicon carbide:germanium heterostructure bipolar transistors," Appl. Phys. Lett., vol. 78, no. 14, p. 2073, 2001.

[22] Z. Hu, X. Liao, H. Diao, G. Kong, X. Zeng, and Y. Xu, "Amorphous silicon carbide films prepared by $\mathrm{H}_{2}$ diluted silane-methane plasma," J. Cryst. Growth, vol. 264, no. 1-3, pp. 7-12, Mar. 2004.

[23] M. Neuschitzer, Y. Sánchez, T. Olar, T. Thersleff, and S. López-, "The complex surface chemistry of kesterites : $\mathrm{Cu} / \mathrm{Zn}$ re-ordering after low temperature post deposition annealing and its role in high performance devices," Chem. Mater., vol. 27, no. 15, pp. 5279-5287, 2015.

[24] M. Colina, A. Morales-Vilches, C. Voz, I. Martín, P. Ortega, A. Orpella, G. López, and R. Alcubilla, "Laser Induced Forward Transfer for front contact improvement in silicon heterojunction solar cells," Appl. Surf. Sci., vol. 336, pp. 89-95, May 2015.

[25] M. Neuschitzer, Y. Sanchez, S. López-Marino, H. Xie, A. Fairbrother, M. Placidi, S. Haass, V. Izquierdo-Roca, A. Perez-Rodriguez, and E. Saucedo, "Optimization of CdS buffer layer for high-performance $\mathrm{Cu}_{2} \mathrm{ZnSnSe}_{4}$ solar cells and the effects of light soaking: elimination of crossover and red kink," Prog. Photovoltaics Res. Appl., vol. 23, no. 11, pp. 1660-1667, Nov. 2015.

[26] T. Anegawa, Y. Oda, T. Minemoto, and H. Takakura, "Comparison of lift-off processes and rear-surface characterization of $\mathrm{Cu}(\mathrm{In}, \mathrm{Ga}) \mathrm{Se}_{2}$ thin films for solar cells," J. Cryst. Growth, vol. 311, no. 3, pp. 742-745, Jan. 2009.

[27] M. J. Kerr, A. Cuevas, and R. a. Sinton, "Generalized analysis of quasisteady-state and transient decay open circuit voltage measurements," J. Appl. Phys., vol. 91, no. 1, p. 399, 2002.

[28] M. Dimitrievska, A. Fairbrother, E. Saucedo, A. Pérez-Rodríguez, and V. Izquierdo-Roca, "Influence of compositionally induced defects on the vibrational properties of device grade $\mathrm{Cu}_{2} \mathrm{ZnSnSe}_{4}$ absorbers for kesterite based solar cells,” Appl. Phys. Lett., vol. 106, no. 7, p. 073903 , Feb. 2015.

[29] M. Dimitrievska, a. Fairbrother, a. Pérez-Rodríguez, E. Saucedo, and V. Izquierdo-Roca, "Raman scattering crystalline assessment of polycrystalline $\mathrm{Cu}_{2} \mathrm{ZnSnS}_{4}$ thin films for sustainable photovoltaic technologies: Phonon confinement model," Acta Mater., vol. 70, pp. 272-280, May 2014.

[30] N. B. Mortazavi Amiri and A. Postnikov, "Electronic structure and lattice dynamics in kesterite-type $\mathrm{Cu}_{2} \mathrm{ZnSnS}_{4}$ from first-principles calculations," Phys. Rev. B, vol. 82, no. 20, p. 205204, Nov. 2010.

[31] M. Dimitrievska, A. Fairbrother, E. Saucedo, A. Pérez-Rodríguez, and Victor Izquierdo-Roca, "Secondary phase and $\mathrm{Cu}$ substitutional defect dynamics in kesterite $\mathrm{Cu}_{2} \mathrm{ZnSnSe}_{4}$ solar cells: impact on optoelectronic properties,” Sol. Energy Mater. Sol. Cells, vol. 149, Pages 304-309, May 2016.

[32] S. Siebentritt, G. Rey, A. Finger, D. Regesch, J. Sendler, T. Paul Weiss, T. Bertram, "What is the bandgap of kesterite?" Sol. Energy Mater. Sol. Cells, in press, 2016. doi:10.1016/j.solmat.2015.10.017 